\title{
Maturação da maçã ‘Gala’ com a aplicação pré-colheita de aminoetoxivinilglicina e ethephon
}

\author{
Maturation of the 'Gala' apple with preharvest sprays of aminoethoxyvynilglycine and ethephon
}

\author{
Cristiano André Steffens ${ }^{1}$ Affonso José Wietzke Guarienti ${ }^{2}$ Lindolfo Storck $^{3}$ Auri Brackmann ${ }^{4}$
}

\section{RESUMO}

O objetivo deste trabalho foi avaliar o efeito da aplicação pré-colheita de aminoetoxivinilglicina (AVG) e ethephon sobre a maturação da maçã 'Gala' colhidas em diferentes datas. Os tratamentos avaliados foram: controle,

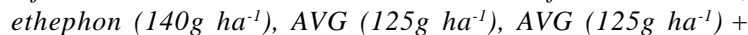
ethephon (140g ha-1), AVG (95g ha-1) e AVG $\left(95 g \mathrm{ha}^{-1}\right)+$ ethephon $\left(140 \mathrm{~g} \mathrm{ha}^{-1}\right)$ em combinação com quatro épocas de colheita (131, 138, 145 e 152 dias após o pleno florescimento). A aplicação pré-colheita de AVG, seguida ou não de ethephon, proporcionou frutos com maior firmeza de polpa, cor de fundo da epiderme mais verde e menor produção de etileno, respiração e índice iodo-amido. Entretanto, o AVG retardou a evolução da cor vermelha dos frutos, principalmente na maior dose. A aplicação de ethephon, em plantas anteriormente tratadas com AVG, proporcionou frutos com cor vermelha semelhante ao tratamento controle sem prejudicar a ação do AVG no controle da maturação dos frutos. O atraso na colheita causou amarelecimento da epiderme, índice iodo-amido mais elevado, alta produção de etileno e menor acidez titulável.

Palavras-chave: Malus domestica Borkh., qualidade, antocianina, etileno.

\section{ABSTRACT}

The objective of this work was to evaluate the effects of preharvest applications of aminoethoxyvinylglycine (AVG) and ethephon on the maturation of the 'Gala' apple harvested on differents dates. The treatments were: control, ethephon (140g ha-1), AVG (125g ha-1), AVG (125g ha-1) + ethephon (140g ha $\left.a^{-1}\right), A V G\left(95 g h a^{-1}\right)$ and AVG $\left(95 g h a^{-1}\right)+$ ethephon $\left(140 \mathrm{~g} \mathrm{ha}^{-1}\right)$. These treatments were combined with 4 harvest date $(131,138,145$ and 152 days after full bloom). The application of AVG, combined or not with ethephon, maintained higher flesh firmness, greener peel color, lower starch index, ethylene and $\mathrm{CO}_{2}$ production. However, AVG retarded the development of the red color of the fruit. The application of ethephon in AVG-treated plants increased the red color of the fruit that was similar to control fruit without influencing effect of AVG on the control of maturation. Delaying harvested fruit showed more yellowing skin color, higher starch index and ethylene production and lower titratable acidity.

Key words: Malus domestica Borkh., quality, anthocyanin, ethylene.

\section{INTRODUÇÃO}

O etileno é um hormônio que regula muitos eventos fisiológicos que culminam na ocorrência das perdas pré e pós-colheita de maçãs, sendo o seu controle um dos principais fatores para a redução das perdas. Vários trabalhos têm demonstrado que o aminoetoxivinilglicina (AVG) diminui a queda précolheita de frutos e retarda a maturação em maçã 'Gala' (AMARANTE et al., 2001; BRACKMANN \& WACLAWOVSKY, 2001; WACLAWOVSKY, 2001). Entretanto, a aplicação de AVG, além de retardar a maturação e melhorar a manutenção da qualidade dos frutos durante o armazenamento, reduz o desenvolvimento da cor vermelha na epiderme de maçãs 'Gala' (AMARANTE et al., 2001; BRACKMANN \& WACLAWOVSKY, 2001; WACLAWOVSKY, 2001). A aparência dos frutos é um critério primordial na

${ }^{1}$ Programa de Pós-graduação em Agronomia da Universidade Federal de Santa Maria (UFSM), Santa Maria, RS, Brasil.

${ }^{2}$ Curso de Agronomia UFSM, Santa Maria, RS, Brasil.

${ }^{3}$ Departamento de Fitotecnia, UFSM, Santa Maria, RS, Brasil.

${ }^{4}$ Departamento de Fitotecnia UFSM, Centro de Ciências Rurais, 97105-900, Santa Maria, RS, Brasil. Email: brackman@ccr.ufsm.br. Autor para correspondência. 
decisão da compra do produto, caracterizada pelo tamanho, forma, cor e ausência de defeito, sendo que a cor contribui mais para a avaliação da qualidade do que os demais fatores. A importância deste atributo de qualidade é ainda maior em maçãs de epiderme vermelha, como a 'Gala', podendo então o AVG reduzir a coloração vermelha e causar problemas na comercialização dos frutos.

O aumento na cor vermelha dos frutos pode ser obtido através da aplicação exógena de etileno, por meio da pulverização dos frutos com ethephon, o que poderá compensar a falta de cor de maçãs tratadas com AVG. Todavia, o ethephon apresenta o inconveniente de acelerar todo o processo de amadurecimento dos frutos. Entretanto, a aplicação de ethephon em frutos anteriormente tratados com AVG pode não estimular o amadurecimento dos frutos pelo fato do AVG inibir a síntese autocatalítica de etileno. De acordo com JU \& CURRY (2000), a aplicação póscolheita de ethephon em frutos tratados com AVG estimulou a síntese de etileno em maçã 'Delicious', mas foi muito menor do que nos frutos do tratamento controle e tratados somente com ethephon. Segundo WANG \& DILLEY (2001), a aplicação de AVG, com subseqüente aplicação do ethephon, reduziu o início do climatério similarmente quando apenas aplicou-se AVG e afetou pouco o desenvolvimento da cor vermelha dos frutos.

Desta forma, o objetivo do trabalho foi de avaliar o efeito da aplicação pré-colheita de aminoetoxivinilglicina (AVG) combinado com o ethephon sobre o controle da maturação de maçãs 'Gala', colhidas em diferentes datas, em especial sobre a cor vermelha dos frutos no momento da colheita.

\section{MATERIAL E MÉTODOS}

O experimento foi conduzido com maçãs (Malus domestica, Borkh.) cultivar Gala, no ano agrícola 2000/2001 em plantas, de 12 anos, de um pomar comercial, no município de Vacaria, RS, (longitude: 5042’ W; latitude: 28³3' S; altitude: 955m).

Os tratamentos constituíram-se da pulverização pré-colheita de soluções com aminoetoxivinilglicina ou ethephon sobre as plantas, em combinação com épocas de colheita, sendo: controle (sem aplicação), ethephon (140g ha-1), AVG (125g ha ${ }^{-1}$ ), AVG (125g ha-1) + ethephon (140g ha $\left.{ }^{-1}\right)$, AVG (95g ha-1) e AVG (95g ha-1) + ethephon (140g ha $\left.{ }^{-1}\right)$, combinados com quatro épocas de colheita, as quais foram131, 138, 145 e 152 dias após o pleno florescimento.

A fonte de AVG foi o produto Retain ${ }^{\circledR}$, com $15 \%$ de ingrediente ativo, aplicado 30 dias antes da primeira colheita. Como fonte de ethephon, foi utilizado o produto Ethrel ${ }^{\circledR}$, com $24 \%$ de ingrediente ativo, aplicado 7 dias antes da primeira colheita. A aplicação dos produtos nas macieiras foi realizada mecanicamente com um turboatomizador, com capacidade de 2000L, acoplado a um trator. O volume da calda utilizado foi de 1000 $\mathrm{L} \mathrm{ha}^{-1}$. O espalhante adesivo utilizado, juntamente com o AVG e ethephon, foi o Iharaguen- $\mathrm{S}^{\circledR}$ (do grupo alquil-fenol- etoxilado na concentração de $0,01 \%$ v/v). A primeira colheita foi determinada a partir da qualidade visual dos frutos, ou seja, pela coloração de fundo da epiderme e pela intensidade da cor vermelha dos frutos do tratamento controle.

Após a colheita, os frutos foram transportados para o Núcleo de Pesquisa em PósColheita da Universidade Federal de Santa Maria, onde foram realizadas as análises laboratoriais para avaliar a maturação. Foram avaliados os seguintes parâmetros: a) Índice iodo-amido: foi determinado pela reação do amido com uma solução com $12 \mathrm{~g}$ de iodo metálico e 24g de iodeto de potássio em 1L de água destilada. Após um corte no na região equatorial dos frutos, foi aplicada a solução de iodo na superfície cortada da metade peduncular do fruto, a cor da qual foi comparada (reação do iodo com o amido) com a tabela de fotografias desenvolvida por STREIF (1984), onde o índice 01 indica o teor máximo de amido, e o índice 10 representa o amido totalmente hidrolisado. b) Produção de etileno: uma subamostra de aproximadamente $1000 \mathrm{~g}$ de cada amostra foi acondicionada em recipientes de 5 litros que, posteriormente, foram fechados, hermeticamente, durante duas horas, a $20^{\circ} \mathrm{C}$. Após este período, utilizando uma seringa plástica de $1 \mathrm{~mL}$, foram coletadas duas amostras da atmosfera do espaço livre destes recipientes, que logo foram injetadas em um cromatógrafo a gás, marca Varian, modelo 3400, equipado com uma coluna de aço inox 1/8” de 0,70m de comprimento, preparada com Porapak N80/100 e um detector de ionização de chama. Utilizou-se $\mathrm{N}_{2}$ como gás de arraste. As temperaturas da câmara de injeção, coluna e detector foram: $90^{\circ} \mathrm{C}, 140^{\circ} \mathrm{C}$ e $200^{\circ} \mathrm{C}$, respectivamente. $\mathrm{O}$ cromatógrafo foi acoplado a um microcomputador com software com curva de calibração, que fornecia os resultados em $\mu \mathrm{L} \mathrm{L}^{-1}$. Através da concentração de etileno, do peso dos frutos, do volume do espaço livre no recipiente e do tempo de fechamento, foi calculada a produção de etileno em $\mu \mathrm{L} \mathrm{C}_{2} \mathrm{H}_{4} \mathrm{~kg}^{-1} \mathrm{~h}^{-1}$; c) Respiração: determinada pela produção de $\mathrm{CO}_{2}$. $\mathrm{O}$ ar do espaço livre do mesmo recipiente que foi utilizado para determinação da síntese de etileno, foi circulado através de um analisador eletrônico de $\mathrm{CO}_{2}$, marca Agri-Datalog, e através da concentração de $\mathrm{CO}_{2}$ determinada no espaço livre do 
recipiente juntamente com a determinação do volume do espaço livre, do peso dos frutos e do tempo de fechamento, foi calculada a respiração em $\mathrm{mL} \mathrm{CO} \mathrm{kg}^{-1}$ $\mathrm{h}^{-1}$; d) Firmeza de polpa: determinada na região equatorial dos frutos, em dois lados opostos, através da remoção de uma pequena porção da epiderme e com auxílio de um penetrômetro equipado com ponteira de 11mm de diâmetro; e) Acidez titulável: determinada em uma amostra de $10 \mathrm{~mL}$ de suco dos frutos, previamente extraído de fatias transversais retiradas da região equatorial das maçãs e trituradas em uma centrífuga elétrica. Esta amostra foi diluída em 100mL de água destilada e titulada com uma solução de hidróxido de sódio $0,1 \mathrm{~N}$ até $\mathrm{pH} 8,1$; f) Cor de fundo da epiderme: determinada através de um colorímetro eletrônico, marca Minolta, modelo CR310, com a seguinte configuração: escala tridimensional de cor CIE L*a*b ou CIELAB, onde o L* representa a claridade, $a^{*}$ indica a variação da cor vermelha ao verde e $b^{*}$ indica a variação da cor amarelo ao azul. Os resultados foram expressos pelo somatório dos valores de a* e $\mathrm{b}^{*}$. Assim, quanto maior o valor desta soma, menos verde ou mais amarela estarão os frutos; e $g$ ) Cor vermelha da epiderme: foi determinada através de uma escala com índices de 1 a 4, em que o índice 1 indicou uma superfície pigmentada de vermelho equivalente de 0 a $20 \%$ da superfície total do fruto, o índice 2 de 21 a 50\%, o índice 3 de 50 a $80 \%$ e o índice 4 de 81 a 100\% da superfície total do fruto.

O delineamento experimental foi o de blocos ao acaso, com seis repetições compostas por 20 frutos cada. Dados em porcentagem foram transformados para $\operatorname{arcosen} \sqrt{\mathrm{x} / 100}$, antes de proceder a análise estatística (análise de variância e teste de Duncan a 5\% de probabilidade).

\section{RESULTADOS E DISCUSSÃO}

A produção de etileno e a respiração foram reduzidas pela aplicação pré-colheita de AVG, seguida ou não pela aplicação de ethephon (Tabela 1). A redução da produção de etileno está, provavelmente, relacionada à inibição da enzima ACC sintase pelo AVG (MASIA et al., 1998; JU \& CURRY, 2000). Outros trabalhos também constataram resultado semelhante nas cultivares Super Red Delicious (FAN et al., 1998), Jonagored Jonagold (MIR et al., 1999), Delicious (JU \& CURRY, 2000), Jonagold (WANG \& DILLEY, 2001) e Gala (BRACKMANN \& WACLAWOVSKY, 2001; WANG \& DILLEY, 2001).

A aplicação de ethephon aumentou a produção de etileno em relação ao tratamento controle
(Tabela 1), confirmando os resultados obtidos em outras cultivares de maçã (LARRIGAUDIERE et al., 1996; FAN et al., 1998; JU \& CURRY, 2000; WANG \& DILLEY, 2001). Este efeito do ethephon deve estar relacionado ao estímulo pelo etileno, liberado através da hidrólise do ethephon, à produção autocatalítica deste hormônio.

Resultado surpreendente foi obtido com a aplicação de ethephon em plantas tratadas anteriormente com AVG, cujos frutos não apresentaram aumento na produção de etileno se comparados com os tratados somente com AVG (Tabela 1). JU \& CURRY (2000) observaram este mesmo resultado do uso combinado destas duas substâncias sobre a cultivar Delicious. Já MIR et al. (1999), nas cultivares Jonagored e Jonagold, verificaram uma produção de etileno intermediária ao tratamento controle e com AVG. WANG \& DILLEY (2001), nas cultivares Jonagold e Gala, também constataram uma produção de etileno nos frutos tratados com AVG e ethephon semelhante aos frutos tratados somente com AVG, sendo que, em algumas avaliações, foi observado até uma menor produção de etileno. Estes resultados devem estar relacionados ao fato do AVG impedir a produção autocatalítica de etileno que seria desencadeada pelo gás liberado do ethephon.

A redução da respiração pelo AVG deve estar relacionado ao efeito desta substância na redução da produção de etileno, pois a respiração parece ser um processo dependente do etileno (PRE-AYMARD et al., 2003).

A aplicação pré-colheita de AVG proporcionou frutos com menor índice de iodo-amido (Tabela 1). Outros trabalhos também mostram a redução da degradação do amido com a aplicação de AVG, nas maçãs cultivares Gala (AMARANTE et al., 2001; WACLAWOVSKY, 2001; WANG \& DILLEY, 2001), e Jonagold (WANG \& DILLEY, 2001) e na pêra 'Bartlett' (CLAYTON et al., 2000). De acordo com WANG \& DILLEY (2001), a degradação do amido é conseqüência direta da indução causada pelo etileno. Embora a produção de etileno tenha sido maior nos frutos tratados com ethephon, talvez a quantidade de etileno produzido pelos frutos do tratamento controle já foi o suficiente para desencadear o processo de degradação do amido.

A firmeza de polpa apresentou maiores valores nos frutos tratados com AVG (Tabela 1), confirmando os resultados de trabalhos em maçã (BRAMLAGE et al., 1980; BRACKMANN \& WACLAWOVSKY, 2000; AMARANTE et al., 2001), pêssego, nectarina (BYERS, 1997), pêra (CLAYTON et al., 2000) e caqui (FERRI et al., 2002). A resposta da 
Tabela 1 - Produção de etileno, respiração, índice iodo-amido e firmeza de polpa de maçãs cv. Gala na colheita em função do tratamento précolheita com aminoetoxivinilglicina (AVG) e ethephon e da data de colheita. Santa Maria, RS, 2003.

\begin{tabular}{|c|c|c|c|c|c|}
\hline Tratamentos & $131 \mathrm{DAPF}^{* *}$ & $138 \mathrm{DAPF}$ & $145 \mathrm{DAPF}$ & 152 DAPF & Média \\
\hline & \multicolumn{5}{|c|}{ Produção de etileno $\left(\mu \mathrm{L} \mathrm{kg}^{-1} \mathrm{~h}^{-1}\right)$} \\
\hline Controle & 0,88 & 1,43 & 1,90 & 0,99 & $1,30 b^{*}$ \\
\hline Ethephon (Eth) (140g ha $\left.{ }^{-1}\right)$ & 1,11 & 1,88 & 3,08 & 1,11 & $1,70 \mathrm{a}$ \\
\hline $\operatorname{AVG}\left(125 \mathrm{~g} \mathrm{ha}^{-1}\right)$ & 0,40 & 0,84 & 1,18 & 0,62 & $0,76 \mathrm{c}$ \\
\hline $\operatorname{AVG}\left(125 \mathrm{~g} \mathrm{ha}^{-1}\right)+$ Eth & 0,33 & 1,02 & 1,24 & 0,44 & $0,76 \mathrm{c}$ \\
\hline $\operatorname{AVG}\left(95 \mathrm{gha}^{-1}\right)$ & 0,80 & 1,17 & 1,28 & 0,59 & $0,96 \mathrm{c}$ \\
\hline AVG (95g ha-1) + Eth & 0,58 & 1,18 & 1,28 & 0,62 & $0,91 \mathrm{c}$ \\
\hline Média & $0,68 \mathrm{C}$ & $0,74 \mathrm{C}$ & $1,61 \mathrm{~A}$ & $1,25 \mathrm{~B}$ & \\
\hline \multirow[t]{2}{*}{$\mathrm{CV}(\%)$} & \multicolumn{5}{|c|}{35,44} \\
\hline & \multicolumn{5}{|c|}{ Respiração (mL CO $\left.\mathrm{kg}^{-1} \mathrm{~h}^{-1}\right)$} \\
\hline Controle & 9,87 & 9,50 & 9,76 & 10,10 & $9,81 \mathrm{a}$ \\
\hline Ethephon (Eth) (140g ha-1) & 10,34 & 10,59 & 9,95 & 10,16 & $10,29 a$ \\
\hline AVG (125g ha-1) & 7,60 & 7,96 & 7,51 & 10,28 & $8,34 \mathrm{~b}$ \\
\hline $\operatorname{AVG}\left(125 \mathrm{~g} \mathrm{ha}^{-1}\right)+$ Eth & 8,96 & 8,74 & 8,64 & 8,37 & 8,68 b \\
\hline AVG (95g ha') & 8,31 & 9,15 & 8,08 & 9,51 & $8,76 \mathrm{~b}$ \\
\hline $\operatorname{AVG}\left(95 g^{h a} a^{-1}\right)+$ Eth & 8,45 & 8,17 & 7,91 & 8,76 & 8,32 b \\
\hline Média & $8,92 \mathrm{AB}$ & $9,58 \mathrm{~A}$ & $8,61 \mathrm{~B}$ & $9,02 \mathrm{AB}$ & \\
\hline \multirow[t]{2}{*}{ CV(\%) } & \multirow{2}{*}{\multicolumn{5}{|c|}{$\begin{array}{c}11,12 \\
\text { Índice iodo-amido (1-10) }\end{array}$}} \\
\hline & & & & & \\
\hline Controle & 6,99 Ba & $7,42 \mathrm{Bb}$ & 8,58 Аа & 8,66 Аа & - \\
\hline Ethephon (Eth) (140g ha-1) & 6,63 Ca & 7,86 Ba & 8,44 Аа & 8,55 Аа & - \\
\hline AVG (125g ha $\left.{ }^{-1}\right)$ & $4,98 \mathrm{Cb}$ & $6,98 \mathrm{Bc}$ & $7,48 \mathrm{Ab}$ & 7,35 Ab & - \\
\hline $\operatorname{AVG}\left(125 \mathrm{~g} \mathrm{ha}^{-1}\right)+$ Eth & 3,63 Dd & 6,56 Ccd & 7,19 Bb & 7,57 Ab & - \\
\hline AVG (95g ha' $\left.{ }^{-1}\right)$ & 4,35 Cc & 6,66 Bcd & $7,44 \mathrm{Ab}$ & 7,74 Ab & - \\
\hline $\operatorname{AVG}\left(95 g a^{-1}\right)+$ Eth & 4,07 Ccd & $6,25 \mathrm{Bd}$ & $7,42 \mathrm{Ab}$ & 7,74 Ab & - \\
\hline \multirow[t]{2}{*}{ CV(\%) } & \multicolumn{5}{|c|}{10,48} \\
\hline & \multicolumn{5}{|c|}{ Firmeza de polpa (N) } \\
\hline Controle & 73,3 & 73,8 & 67,0 & 70,9 & 71,2 c \\
\hline Ethephon (Eth) (140g ha $\left.{ }^{-1}\right)$ & 76,7 & 72,4 & 69,3 & 71,1 & $72,4 \mathrm{c}$ \\
\hline AVG (125g ha $\left.{ }^{-1}\right)$ & 77,9 & 73,5 & 74,4 & 77,8 & $75,9 \mathrm{ab}$ \\
\hline $\operatorname{AVG}\left(125 \mathrm{~g} \mathrm{ha}^{-1}\right)+$ Eth & 80,6 & 76,0 & 76,0 & 80,5 & 78,3 a \\
\hline AVG (95g ha" $\left.{ }^{-1}\right)$ & 78,2 & 73,7 & 72,9 & 76,0 & 75,2 b \\
\hline $\operatorname{AVG}\left(95 \mathrm{~g} \mathrm{ha}^{-1}\right)+$ Eth & 80,8 & 76,8 & 74,0 & 78,3 & $77,5 \mathrm{ab}$ \\
\hline Média & 77,9 A & $74,4 \mathrm{BC}$ & 72,3 C & $75,8 \mathrm{AB}$ & \\
\hline CV(\%) & & & 6,32 & & \\
\hline
\end{tabular}

* Médias seguidas pela mesma letra, maiúsculas na horizontal e minúsculas na vertical, não diferem estatisticamente pelo teste de Duncan em $5 \%$ de probabilidade de erro.

** DAPF = dias após pleno florescimento

firmeza de polpa ao AVG está diretamente relacionada à redução na produção de etileno dos frutos. De acordo com os resultados de JOHNSTON et al. (2001) e MAJUMDER \& MAZUMDAR (2002), a presença de etileno é necessária para a atividade das enzimas responsáveis pela perda de firmeza de polpa. MAJUMDAR \& MAZUMDER (2002) constataram que o aumento na atividade da poligalacturonase foi altamente correlacionado com a evolução de etileno.

A aplicação de ethephon, em plantas não tratadas com AVG, não reduziu a firmeza de polpa dos frutos (Tabela 1). Entretanto, WANG \& DILLEY (2001) observaram maior perda de firmeza de polpa com o tratamento de ethephon. Embora os frutos tratados somente com ethephon tenham produzido mais etileno, possivelmente a produção de etileno pelos frutos do tratamento controle foi suficiente para atingir uma concentração interna de etileno fisiologicamente ativa para o processo de degradação da parede celular.

Foi verificado também um efeito sinérgico do AVG e ethephon sobre a manutenção da firmeza de polpa (Tabela 1). WANG \& DILLEY (2001) obtiveram, 
na maçã 'Gala', um efeito sinérgico ainda maior destas duas substâncias, em um dos dois anos em que realizaram os experimentos. Entretanto, na cultivar Jonagold, este efeito sinérgico não foi observado, mas os frutos apresentaram firmeza de polpa semelhante aqueles que foram tratados somente com AVG (WANG \& DILLEY, 2001).

A acidez titulável não apresentou diferença estatística entre os tratamentos pré-colheita (Tabela 2). WACLAWOVSKY (2001) também não verificou efeito do AVG sobre a acidez titulável da maçã 'Gala'.

A aplicação pré-colheita de AVG, seguida ou não da aplicação de ethephon, manteve a epiderme dos frutos mais verde, principalmente na concentração de $125 \mathrm{~g} \mathrm{ha}^{-1}$ (Tabela 2). WACLAWOVSKY (2001) e AMARANTE et al. (2001) também obtiveram maçãs 'Gala' mais verdes com a aplicação pré-colheita de AVG, afirmando que a cor de fundo da epiderme é um dos parâmetros mais afetados pelo AVG.
Este efeito do AVG sobre a redução do amarelecimento da epiderme deve estar relacionado com a menor atividade das enzimas que estão envolvidas na degradação das clorofilas. FERRI et al. (2002) citam que o AVG atua inibindo a síntese e/ou a atividade das clorofilases, porém afirmam que o mecanismo não está bem esclarecido. Provavelmente, este efeito seja indireto, ou seja, devido à menor produção de etileno pelos frutos, pois JOHNSTON et al. (2002) constataram que o início do amarelecimento de maçã coincidiu com o aumento na concentração interna de etileno, além do que frutos expostos ao etileno apresentaram maior atividade de enzimas degradadoras de clorofilas.

O índice de cor vermelha foi maior em frutos das plantas que receberam somente aplicação de ethephon (Tabelas 2). O índice de cor vermelha foi negativamente afetado pelo AVG (Tabela 2). AMARANTE et al. (2001), WACLAWOVSKY (2001) e WANG \& DILLEY (2001) também constataram, em

Tabela 2 - Cor da epiderme e acidez titulável de maçãs cv. Gala na colheita em função do tratamento pré-colheita com aminoetoxivinilglicina (AVG) e ethephon e da data de colheita. Santa Maria, RS, 2003.

\begin{tabular}{|c|c|c|c|c|c|}
\hline Tratamentos & $131 \mathrm{DAPF}^{* *}$ & 138 DAPF & 145 DAPF & 152 DAPF & Média \\
\hline & \multicolumn{5}{|c|}{ Cor vermelha da epiderme (1-4) } \\
\hline Controle & 2,38 & 2,30 & 2,37 & 2,35 & $2,35 b^{*}$ \\
\hline Ethephon (Eth) $\left(140 \mathrm{~g} \mathrm{ha}^{-1}\right)$ & 2,62 & 2,42 & 2,43 & 2,40 & $2,46 \mathrm{a}$ \\
\hline $\operatorname{AVG}\left(125 \mathrm{~g} \mathrm{ha}^{-1}\right)$ & 2,10 & 1,90 & 2,14 & 2,09 & $2,06 \mathrm{~d}$ \\
\hline $\operatorname{AVG}\left(125 \mathrm{~g} \mathrm{ha}^{-1}\right)+$ Eth & 2,27 & 2,14 & 2,28 & 2,34 & $2,26 \mathrm{bc}$ \\
\hline AVG (95g ha $\left.{ }^{-1}\right)$ & 2,09 & 2,05 & 2,32 & 2,20 & $2,17 \mathrm{c}$ \\
\hline $\operatorname{AVG}\left(95 \mathrm{~g} \mathrm{ha}^{-1}\right)+$ Eth & 2,26 & 2,09 & 2,32 & 2,35 & 2,25 bc \\
\hline Média & $2,28 \mathrm{~A}$ & $2,15 \mathrm{~B}$ & $2,31 \mathrm{~A}$ & $2,29 \mathrm{~A}$ & \\
\hline \multirow[t]{2}{*}{ CV(\%) } & & & & & \\
\hline & \multicolumn{5}{|c|}{ Cor de fundo (CIE $\left.-a^{*}+b^{*}\right)$} \\
\hline Controle & $45,3 \mathrm{Ca}$ & $44,9 \mathrm{Cb}$ & $53,2 \mathrm{Ba}$ & 57,9 Aab & - \\
\hline Ethephon (Eth) (140g ha $\left.{ }^{-1}\right)$ & $42,6 \mathrm{Db}$ & $47,7 \mathrm{Ca}$ & $53,1 \mathrm{Ba}$ & 59,9 Аа & - \\
\hline $\operatorname{AVG}\left(125 \mathrm{~g} \mathrm{ha}^{-1}\right)$ & $39,3 \mathrm{Bc}$ & $40,6 \mathrm{Bc}$ & $40,7 \mathrm{Bc}$ & 49,4 Ad & - \\
\hline $\operatorname{AVG}\left(125 \mathrm{~g} \mathrm{ha}^{-1}\right)+$ Eth & $35,0 \mathrm{Dd}$ & $38,6 \mathrm{Cc}$ & $41,6 \mathrm{Bc}$ & $53,0 \mathrm{Ac}$ & - \\
\hline AVG $\left(95 g^{h a} a^{-1}\right)$ & 37,3 Dcd & 40,4 Cc & $46,0 \mathrm{Bb}$ & 53,9 Ac & - \\
\hline $\operatorname{AVG}\left(95 \mathrm{gha}^{-1}\right)+$ Eth & 35,2 Dd & $40,0 \mathrm{Cc}$ & $47,7 \mathrm{Bb}$ & $57,3 \mathrm{Ab}$ & - \\
\hline \multirow[t]{2}{*}{ CV(\%) } & \multicolumn{5}{|c|}{8,31} \\
\hline & \multicolumn{5}{|c|}{ Acidez titulável $\left(\mathrm{cmol} \mathrm{L}^{-1}\right)$} \\
\hline Controle & 5,44 & 4,94 & 4,69 & 4,80 & 4,97 a \\
\hline Ethephon (Eth) $\left(140 \mathrm{~g} \mathrm{ha}^{-1}\right)$ & 5,48 & 5,01 & 4,87 & 5,19 & 5,13 a \\
\hline AVG (125g ha $\left.{ }^{-1}\right)$ & 5,24 & 4,75 & 4,63 & 5,16 & 4,94 a \\
\hline $\operatorname{AVG}\left(125 \mathrm{~g} \mathrm{ha}^{-1}\right)+$ Eth & 5,40 & 4,96 & 4,97 & 4,92 & 5,06 a \\
\hline $\operatorname{AVG}\left(95 \mathrm{gha}^{-1}\right)$ & 5,77 & 5,06 & 4,98 & 5,26 & 5,25 a \\
\hline $\operatorname{AVG}\left(95 g^{-1}\right)+$ Eth & 5,63 & 5,17 & 5,04 & 5,38 & 5,29 a \\
\hline Média & $5,48 \mathrm{~A}$ & $4,98 \mathrm{BC}$ & $4,86 \mathrm{C}$ & $5,12 \mathrm{~B}$ & \\
\hline $\mathrm{CV}(\%)$ & & & 9,52 & & \\
\hline
\end{tabular}

* Médias seguidas pela mesma letra, maiúsculas na horizontal e minúsculas na vertical, não diferem estatisticamente pelo teste de Duncan em $5 \%$ de probabilidade de erro.

** DAPF $=$ dias após pleno florescimento

Ciência Rural, v.36, n.2, mar-abr, 2006. 
'Gala', redução da cor vermelha devido à aplicação de AVG. De acordo com AWAD \& de JAGER (2002), a redução na cor vermelha de maçãs 'Jonagold', pelo AVG, foi conseqüência de uma diminuição significativa na produção de antocianinas, sendo que estes pigmentos respondem mais rapidamente a tratamentos promotores e inibidores de etileno, do que outros fenômenos relacionados ao amadurecimento. Estes autores sugeriram ainda que o AVG, pela inibição da síntese de etileno, pode suprimir a expressão dos genes relacionados à biossíntese de antocianinas. No momento em que o etileno endógeno atinge um nível crítico, ele ativa os genes envolvidos na biossíntese de antocianinas.

A aplicação de ethephon em plantas anteriormente tratadas com AVG proporcionou frutos com índice de cor vermelha semelhante ao do tratamento controle (Tabela 2), possivelmente por compensar o efeito negativo do AVG sobre a síntese de pigmentos antociânicos. WANG \& DILLEY (2001) observaram este mesmo efeito da associação do AVG e ethephon em maçãs ‘Gala' e ‘Jonagold'. De acordo com MURPHEY \& DILLEY (1988), o aumento da biossíntese de antocianinas pode requerer somente uma breve exposição ao etileno, a qual pode ser insuficiente para afetar outras características do amadurecimento. De acordo com outros trabalhos, o etileno pode atuar sobre a atividade de algumas enzimas que atuam na rota de biossíntese de antocianinas (LI et al., 2002).

Quanto à data de colheita, observou-se aumento na síntese de etileno e no índice de iodoamido com o atraso da data de colheita, além de uma redução da firmeza de polpa e acidez titulável e o amarelecimento dos frutos (Tabelas 1 e 2). Estes resultados são um comportamento normal devido ao avanço da maturação, sendo que também foi observado por ARGENTA \& MONDARDO (1994), BOWEN \& WATKINS (1997) e WANG \& DILLEY (2001).

\section{CONCLUSÕES}

A aplicação de AVG retarda a maturação da maçã 'Gala' em até duas semanas, porém causa uma leve redução na cor vermelha dos frutos. A aplicação de ethephon em macieira anteriormente tratadas com AVG, anula o efeito negativo do AVG na formação da cor vermelha da epiderme, sem prejudicar a ação do AVG no retardamento da maturação dos frutos, podendo até haver sinergismo entre as duas substâncias na manutenção de uma alta firmeza da polpa.

\section{REFERÊNCIAS}

AMARANTE, C.V.T. do et al. Preharvest treatment with aminoethoxyvinylglycine (AVG) delays fruit maturity of apples.
In: CONGRESSO BRASILEIRO DE FISIOLOGIA VEGETAL, 8., 2001, Ilhéus. Anais... Ilhéus: SBFV, 2001. CD ROM.

ARGENTA, L.C.; MONDARDO, M. Maturação na colheita e qualidade de maçãs 'Gala' após a armazenagem. Revista Brasileira de Fisiologia Vegetal, São Carlos, v.6, n.2, p.135140, 1994

AWAD, M.A.; de JAGER, A. Formation of flavonoids, especially anthocyanin and chlorogenic acid in 'Jonagold' apple skin: influences of growth regulators and fruit maturity. Scientia Horticulturae, Amsterdam, v.93, n.3-4, p.257-266, 2002.

BOWEN, J.H.; WATKINS, C.B. Fruit maturity, carbohydrate and mineral content relationships with watercore in 'Fuji' apples. Postharvest Biology and Technology, Amsterdam, v.11, n.1, p.31-38, 1997.

BRACKMANN, A.; WACLAWOVSKY, A.J. Responses of 'Gala' apples to preharvest treatment with AVG and low ethylene CA storage. Acta Horticulturae, Leuven, n.553, p.155-157, 2001.

BRACKMANN, A.; WACLAWOVSKY, A.J. Efeitos do Retain em pós-colheita. In: ENCONTRO NACIONAL DE FRUTICULTURA DE CLIMA TEMPERADO - ENFRUTE, 3., 2000, Fraiburgo. Anais... Caçador: EPAGRI, 2000. p.93-98.

BRAMLAGE, W.J. et al. Effects of aminoethoxyvinylglycine on internal ethylene concentrations and storage of apples. Journal of the American Society of Horticultural Science, Alexandria, v.105, n.6, p.847-851, 1980.

BYERS, R.E. Peach and nectarine fruit softening following aminoethoxyvinylglycine sprays and dips. HortScience, Alexandria, v.32, n.1, p.86-88, 1997.

CLAYTON, M. et al. ReTain ${ }^{\mathrm{TM}}$ affects maturity and ripening of 'Bartlett' pear. HortScience, Alexandria, v.35, n.7, p.12941299, 2000 .

FAN, X.T. et al. Continuous requirement of ethylene for apple fruit volatile synthesis. Journal of Agricultural and Food Chemistry, Washington, v.46, n.5, p.1959-1963, 1998.

FERRI, V.C. et al. Controle da maturação de caquis 'Fuyu' com uso de aminoetoxivinilglicina e ácido giberélico. Revista Brasileira de Fruticultura, Jaboticabal, v.24, n.2, p.344347, 2002

JOHNSTON, J.W. et al. Temperature and ethylene affect induction of rapid softening in 'Granny Smith' and 'Pacific Rose $^{\mathrm{TM}}$, apple cultivars. Postharvest Biology and Technology, Amsterdam, v.25, n.3, p.257-267, 2002.

JOHNSTON, J.W. et al. Temperature induces differential softening responses in apple cultivars. Postharvest Biology and Technology, Amsterdam, v.23, n.3, p.185-196, 2001.

JU, Z.; CURRY, E.A. Evidence that $\alpha$-farnesene biosynthesis during fruit ripening is mediated by ethylene regulated gene expression in aplles. Postharvest Biology and Technology, Amsterdam, v.19, n.1, p.9-16, 2000.

LARRIGAUDIERE, C. et al. Differential effects of ethephon and seniphos on color developmental of 'Starking Delicious' 
apple. Journal of the American Society for Horticultural Science, Alexandria, v.121, n.4, p.746-750, 1996.

LI, Z. et al. Stimulation of 'Fuji' apple skin color bu ethephon and phosphorus-calcium mixed compounds in relation to flavonoid synthesis. Scientia Horticulturae, Amsterdam, v.94, n.1-2, p.193-199, 2002.

MAJUMDER, K.; MAZUMDAR, B.C. Changes of pectic substances in developing fruits of cape-gooseberry (Physalis peruviana L.) in relation to the enzyme activity and evolution of ethylene. Scientia Horticulturae, Amsterdam, v.96, n.14, p.91-101, 2002.

MASIA, A. et al. Effect of some plant growth regulator treatments on apple fruit ripening. Plant Growth Regulator, Dordrecht, v.25, n.2, p.127-134, 1998

MIR, N.A. et al. Relationship between ethylene response manipulation and volatile production in Jonagold variety apples. Journal of Agricultural and Food Chemistry, Washington, v.47, n.7, p.2653-2659, 1999.

MURPHEY, A.S.; DILLEY, D.R. Anthocyanin biosynthesis and maturity of McIntosh apples as influenced by ethylene- releasing compounds. Journal of the American Society for Horticultural Science, Alexandria, v.113, n.2, p.718-723, 1988.

PRE-AYMARD, C. et al. Responses of 'Anna', a rapidly ripning summer apple, to 1-methylcyclopropene. Postharvest Biology and Technology, Amsterdam, v.27, n.2, p.163-170, 2003.

STREIF, J. Jod-Stärke-test zur beurteilung der fruchtreife bei Äpfeln. Obst und Garten, Stuttgart, n.8, p.12, 1984.

WACLAWOVSKY, A.J. Controle da maturação de maçãs (Malus domestica Borkh.) cv. Gala, com aplicação précolheita de aminoetoxivinilglicina (AVG). 2001. $134 \mathrm{f}$. Dissertação (Mestre em Agronomia) - Universidade Federal de Santa Maria, Santa Maria, RS.

WANG, Z.; DILLEY, D.R. Aminoethoxyvinylglycine, combined with ethephon, can enhance red color development without over-ripening apples. HortScience, Alexandria, v.36, n.2, p.328-331, 2001. 